This manuscript was accepted and published by the Thermochimica Acta.

Publication data of the final, corrected work:

Várhegyi, G.; Till, F.: Computer processing of thermogravimetric - mass

spectrometric and high pressure thermogravimetric data. Part 1. Smoothing and

differentiation. Thermochim. Acta 1999, 329, 141-145. doi: 10.1016/S0040-

6031(99)00041-6

\title{
Computer processing of thermogravimetric - mass spectrometric and high pressure thermogravimetric data. Part 1. Smoothing and differentiation.
}

\author{
Gábor Várhegyi * and Ferenc Till \\ Research Laboratory of Materials and Environmental Chemistry, \\ Chemical Research Center, Hungarian Academy of Sciences \\ *Email: varhegyi.gabor@t-online.hu or gvarhegyi@gmail.com
}

\begin{abstract}
High quality data smoothing is frequently required in the thermal analysis. Though the mathematical methods for smoothing are well known, the selection of the proper smoothing parameters cannot be based on statistical checks alone in thermal analysis. Many times a compromise must be found between the effective removal of the various experimental error components and the distortion of the curves by too strong smoothing. The following topics are discussed from a practical point of view: (i) the determination of the derivative thermogravimetric (DTG) curves at low sample masses; (ii) the elimination of the noise and flutter from the results of high-pressure TG experiments; (iii) the evaluation of the noisy, low intensity mass spectrometric signals arising from the minor volatile products of decomposition or oxidation. The performance of the methods is shown in two applications: Evaluation $0.25-0.5 \mathrm{mg}$ mass loss steps in high-pressure thermogravimetry; (2) Study of $\mathrm{NO}_{\mathrm{x}}$ formation by atmospheric pressure thermogravimetry - mass spectrometry during the temperature programmed combustion of $0.4 \mathrm{mg}$ coal char.
\end{abstract}

Keywords: Thermogravimetry - mass spectrometry, high-pressure thermogravimetry, smoothing, differentiation, DTG 


\section{Introduction}

The authors have been working in a research team dealing with the development and application of thermoanalytical methods for thirty years. A fully computerized thermobalance - mass spectrometer system was built in 1979 [1] which helped us in the study of a wide range of organic and inorganic substances [2-9]. Recently a high-pressure thermobalance was built to measure the thermal decomposition and temperature programmed combustion of 1- $5 \mathrm{mg}$ samples at elevated pressures. Altogether about 3000 thermogravimetric (TG) and thermogravimetric - mass spectrometric (TG-MS) experiments have been recorded by computerized data acquisition in our laboratory since 1980. Most of these data are still stored online together with ca. 10,000 files containing graphics and tables about the experiments. We developed software for the acquisition, handling and processing of these data. From a theoretical point of view, the software is based on well-known mathematical principles. There are however, several practical aspects of the handling of thermal analysis data which cannot be derived from mathematical theories. In this series of papers we wish to summarize those parts of our 30-year experience in thermal analysis software development which may help the other researchers of this field.

The present issue deals with smoothing problems. The following topics will be discussed: (i) the determination of the DTG curves at low sample masses; (ii) the elimination of the noise and flutter from the results of high-pressure TG experiments; (iii) the evaluation of the noisy, low intensity mass spectrometric signals arising from the volatile minor products of decomposition or oxidation. In our work we found the use of low sample masses extremely important in order to achieve a true kinetic control. When processes with high heats of reaction are studied, we frequently have to employ sample masses of $0.2-0.5 \mathrm{mg}$ to avoid self-heating/self cooling phenomena $[10,11]$. In the present paper the performance of the methods is shown in two applications: (1) Evaluation $0.25-0.5 \mathrm{mg}$ mass loss steps in elevatedpressure thermogravimetry; (2) Study of $\mathrm{NO}_{\mathrm{x}}$ formation by atmospheric pressure thermogravimetry mass spectrometry during the temperature programmed combustion of $0.4 \mathrm{mg}$ coal char. The sample masses employed in these examples were much lower than the usual values in the literature (15 - 1000 $\mathrm{mg}$ in high-pressure thermogravimetry and $5 \mathrm{mg}$ in $\mathrm{NO}_{\mathrm{x}}$ studies by TG-MS). We worked near to the sensitivity limits of the apparatuses, which required the considerations outlined in this paper. 


\section{Experimental}

\subsection{TG-MS apparatus}

A computerized atmospheric pressure thermobalance - mass spectrometer (TG - MS) system was built earlier from a Perkin Elmer TGS - 2 thermobalance and a Balzers QMG - 511 mass spectrometer [1, 2]. Recently a Hiden HAL 3F/PIC mass spectrometer with a fast ion counter was built into the system. 1 - 128 peak intensities can be selected for recording as functions of time. The gases formed are led from the TG furnace to the ion source through a heated capillary. The sensitivity of the equipment was checked in test experiments by using $0.05 \mathrm{mg}$ samples [12]. The intensity curves are corrected by their baseline shift during the experiments. Intensities $\mathrm{m} / \mathrm{z} 16$ and 28 are corrected by taking into account the fragmentation of $\mathrm{H}_{2} \mathrm{O}$ and $\mathrm{CO}_{2}$. The amount of ${ }^{13} \mathrm{CO}^{+}$and $\mathrm{C}^{18} \mathrm{O}^{+}$isotope ions are subtracted from intensities $\mathrm{m} / \mathrm{z} 29$ and 30 .

\subsection{High pressure thermogravimetry}

A Hiden IGA high pressure microbalance system was equipped by an alumina furnace. The temperature of the furnace is programmed by an Eurotherm 906 EPC programmer. Elevated pressure gas (up to $20 \mathrm{bar}$ ) is led to the furnace so that the pressure surrounding the furnace was identical with the pressure inside. The pressure is regulated with an Aalborg PSV-1 proportional solenoid valve and an Omega CN 76163-PV programmer unit. The gas flow rate is controlled at the outlet of the system, at room temperature and atmospheric pressure by an ASM AFC-260 flow controller.

\subsection{Computers and computer languages}

PC compatible computers were used under Windows 95 operating system. The programs run as "console applications" (in a DOS-window) passing the graphic information to a Windows-application for viewing and printing. The programs were written in languages Fortran 77, Fortran 90 and C++. An IMSL library routine (subroutine DCSSMH in Microsoft's Fortran PowerStation) was used for spline smoothing.

\section{Discussion}

\subsection{Determination of the DTG curves in atmospheric thermogravimetry}

The experimental errors we wish to filter out contain random and non-random components. The smoothing of the random part of the errors is a well-defined problem which can be solved by well established mathematical methods. One has to estimate the noise level of a given curve by simple statistical checks, then find a "smooth" $\mathrm{f}(\mathrm{t})$ function approximating the experimental data within the given noise level: 


$$
\sum_{i=1}^{N} w_{i}^{2}\left(f\left(t_{i}\right)-X_{i}\right)^{2} \leq N \sigma^{2}
$$

Here $N, f(t), t, X_{i}$ and $\sigma$ denote the number of data, the smoothing function, the time, the observations, and the noise level, respectively. The role of weight factors $\mathrm{w}_{\mathrm{i}}$ will be discussed in the next paragraph. In atmospheric pressure thermogravimetry we can use $\mathrm{w}_{\mathrm{i}} \equiv 1$ values. This type of smoothing was invented by Whittaker more then 70 years ago [13], who gave an elegant mathematical formulation for equation (1). Later Reinsch [14] developed an effective algorithm for the calculation of cubic spline functions satisfying conditions (1) - (2). This method is now part of every major mathematical program library.

For the estimation of the random, independent component of the errors we may consider that the thermoanalytical curves are usually smooth and can be well approximated by polynomials in short intervals. We can compare the experimental $\mathrm{X}_{\mathrm{i}}$ data to $\mathrm{P}_{\mathrm{i}}$ values calculated from their neighboring points by third order polynomial interpolation:

$$
P_{i}=\left[4\left(X_{i-1}+X_{i+1}\right)-X_{i-2}-X_{i+2}\right] / 6
$$

The $\left(\mathrm{P}_{\mathrm{i}}-\mathrm{X}_{\mathrm{i}}\right)$ differences are characteristic to the random noise. The variance of formula (3) is $(34 / 36) \sigma^{2} \cong 0.94 \sigma^{2}$. Hence the variance of $\left(\mathrm{P}_{\mathrm{i}}-\mathrm{X}_{\mathrm{i}}\right)$ is $1.94 \sigma^{2}$ and the right hand side of condition (2) can be estimated by

$$
(\mathrm{N}-4) \sigma^{2} \approx \sum_{\mathrm{i}=3}^{\mathrm{N}-2}\left(\mathrm{P}_{\mathrm{i}}-\mathrm{X}_{\mathrm{i}}\right)^{2} / 1.94
$$

The smoothing of the random noise, however, is not enough when low, wide DTG peaks are evaluated at low sample masses. Sometimes we have to deal with the non-statistical noise at higher sample masses, too (when the mass loss is more than $1 \mathrm{mg}$ ), due to such phenomena as the vibration of the building or the accumulation of electrostatic charge on the sample holder. In such situations the noise level in equation (2) should be gradually increased and the resulting graphics on the screen should be surveyed. A compromise should be found between the waves appearing on the DTG or mass spectrometric intensity curves and the distortion of the curves by too strong smoothing. 

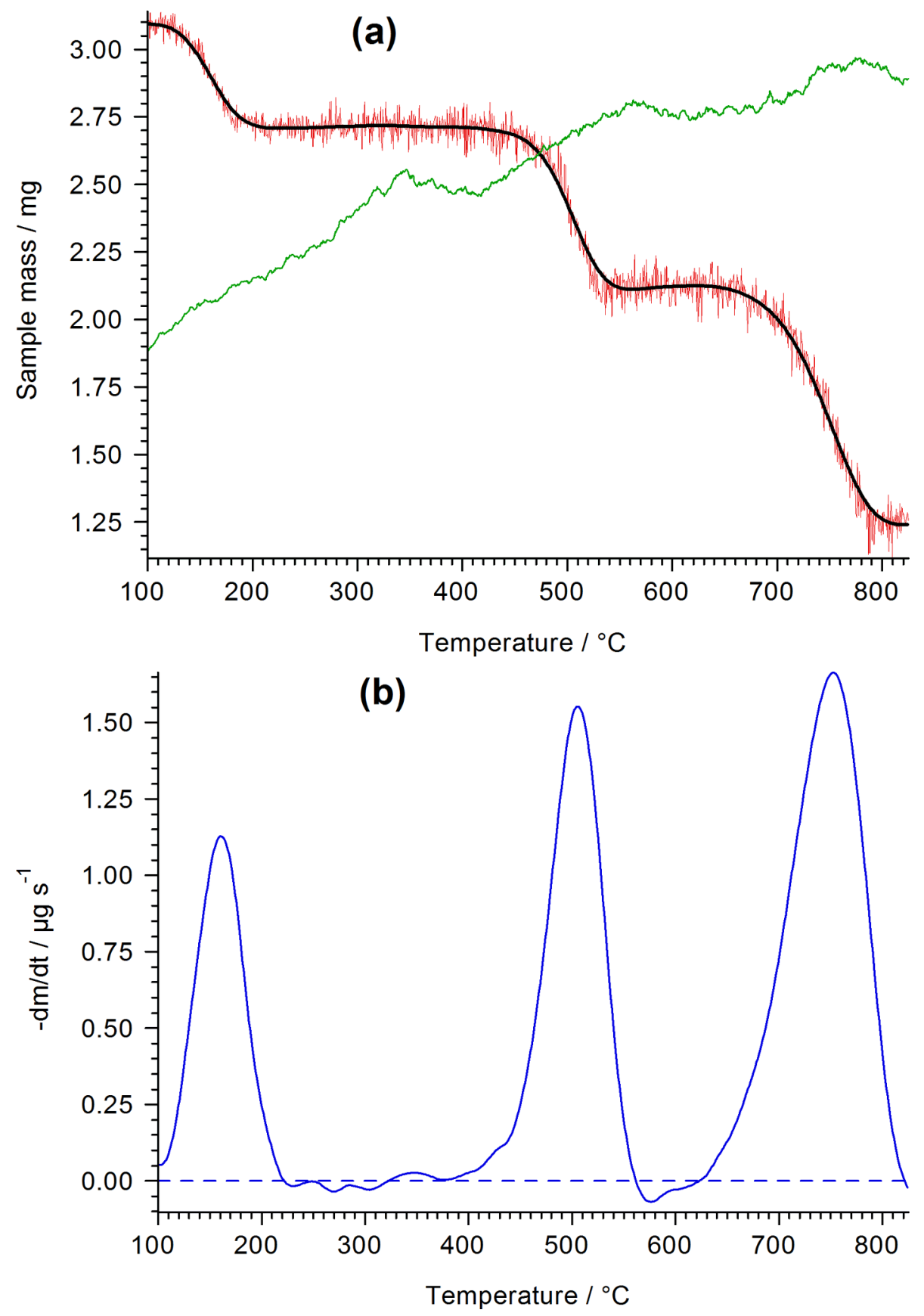

Figure 1: Evaluation $0.25-0.5 \mathrm{mg}$ mass loss steps in high-pressure thermogravimetry. $3 \mathrm{mg} \mathrm{CaC}_{2} \mathrm{O}_{4} \cdot \mathrm{H}_{2} \mathrm{O}$ was decomposed at 6 bar pressure and $10^{\circ} \mathrm{C} / \mathrm{min}$ heating rate, in argon flow. Panel (a) shows the smoothing of the TG data and the temperature dependence of the $s_{i}$ deviations (see the text, below). Panel (b) displays the resulting DTG curve.

\subsection{Smoothing high-pressure experiments}

In high-pressure thermogravimetry, turbulence and fluctuation phenomena hinder the precise weight measurement. The magnitude of these errors depends on the temperature. Particular care is needed to take into account this temperature dependence by suitable weight factors in equation (2). According to our experience, the following method gives satisfying results:

1) We do not employ any hardware filter during the experiment, since a properly selected computer smoothing is much more effective. 
2) We read the weight values approximately every millisecond. From these data we calculate and store the averages and standard deviations in time intervals of a few seconds.

3) We form weight factors for inequality (2) from the reciprocal of the recorded deviation data. It turned out that the smoothing is more effective if we smooth the recorded deviations by some simple method (e.g. moving averages) before forming the weight factors. The deviation values obtained in this way will be denoted as $\mathrm{s}_{\mathrm{i}}$. They can be used as an experimental approximation for the temperature dependence of the reliability of the experimental data.

4) Since the $s_{i}$ values and the $\left(f\left(t_{i}\right)-X_{i}\right)$ differences have the same dimension $(m g), \sigma$ in in inequality (2) becomes a dimensionless smoothing parameter. An initial value of $\sigma$ can easily be found if we introduce the $\mathrm{w}_{\mathrm{i}}=1 / \mathrm{s}_{\mathrm{i}}$ weight factors into the sum of equation (4), too.

Figure 1 shows the application of the above method for the smoothing and differentiation of a high pressure TG curve consisting of $0.25-0.5 \mathrm{mg}$ mass-loss steps.

\section{Fast smoothing of huge data sets}

In thermogravimetry - mass spectrometry we have to evaluate frequently the low intensity mass spectrometric signals of minor volatile products. In case of unfavorable signal/noise ratios a strong smoothing has to be employed and a particular care is needed in controlling its systematic distortion. We usually wish to compare the temperature dependence and shape of these curves to other MS curves and to the DTG. (See references [2-3] for examples.) For such comparisons it is desirable to employ smoothing with the same distortion for all curves of a given experiment. This can easily achieved by any smoothing method which is a linear mathematical operation, among others by methods based on least squares polynomial approximation. Suppose that the observed signal is the sum of a theoretical curve, $X^{\text {theor }}(t)$, and various $n_{j}(t)$ noise components:

$$
\mathrm{X}^{\mathrm{obs}}(\mathrm{t})=\mathrm{X}^{\text {theor }}(\mathrm{t})+\sum \mathrm{n}_{\mathrm{j}}(\mathrm{t})
$$

If the $X^{\text {theor }}(t)$ functions of a group of MS intensity curves differ only in constant multipliers and in nearly linear base line shifts, then the distortion caused by a least squares polynomial smoothing will be the same, hence the systematic error of the smoothing will not decrease the similarity of the curves. Another requirement is the high computational speed. The user may wish to try different levels of smoothing for the whole data set, display the curves and select the smoothing parameters optimal for the given purpose.

The Savitzky - Golay filters [15] satisfy the above requirements. In this method least squares polynomial sections are slid through the domain of the curves. Each polynomial section approximates L points. (The choice of $\mathrm{L}$ is discussed below). The central points of the polynomials are used for the smoothing. (Except of course the end sections of the domain, where more values have to be calculated 
from the smoothing polynomials.) This well-known and widely-used method was invented at the beginning of the century [13] and it is still being developed nowadays [16].

We employ this method with third order polynomials with a user-selected length. According to our experience, the following practical considerations may help the finding of the proper smoothing level in thermogravimetry - mass spectrometry:

a) A third order polynomial can reasonably approximate wave-like noise components which have one maximum and one minimum in the given interval. Hence the method does not filter out the waves with wavelength higher than or approximately equal to L. It becomes very effective for noises with wavelength much smaller than L.

b) L must remain safely below the width of the DTG and MS peaks of the given experiments.

c) The systematic error of the smoothing can easily be checked in the following way. We can select a well-defined curve with a high signal/noise ratio in the given experiment and survey the height and shape of this curve at different $\mathrm{L}$ values on the screen. The graphics may be restricted to the peak(s) where the systematic errors of the smoothing are the most apparent.

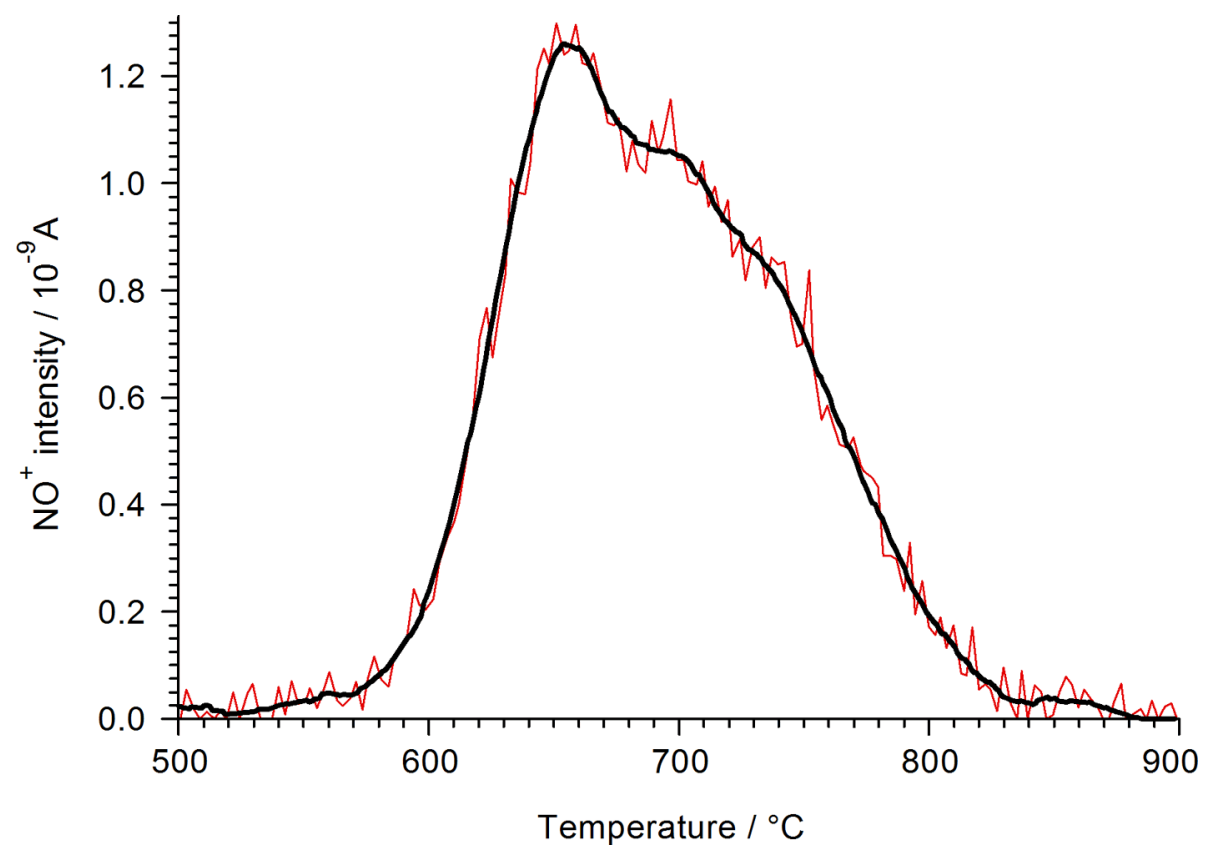

Figure 2: Smoothing an $\mathrm{NO}^{+}$intensity curve measured in the temperature programmed combustion of $0.4 \mathrm{mg}$ coal char at $50^{\circ} \mathrm{C} / \mathrm{min}$ heating rate.

The Savitzky - Golay smoothing of mass spectrometric curves is illustrated by Figure 2, which shows the intensity of the NO+ ions during the temperature programmed combustion of $0.4 \mathrm{mg}$ coal char at $50^{\circ} \mathrm{C} / \mathrm{min}$ heating rate. The char was prepared from a high-volatile bituminous Polish coal at $950^{\circ} \mathrm{C}$ [10]. The double peak appearing on Figure 2 is characteristic to the temperature programmed combustion 
of that char [10]. The L smoothing parameter was chosen to 21 points which corresponds to 60 seconds or $50^{\circ} \mathrm{C}$ in this experiment.

\section{Acknowledgments}

This work was supported by the Hungarian National Research Fund (OTKA T016173 and T025347), the Academic Research Fund (AKP 96-93/23) and the U.S. Hungarian Joint Fund (Grant 93b375). The authors thank Drs. Emma Jakab and Piroska Szabó for their help.

\section{References}

[1] T. Székely, F. Till and G. Várhegyi: Characterisation of fossil fuels by computer aided thermobalance - mass spectrometer system. Proc. 6th Internat. Conf. Thermal Anal. (Ed.: W. Hemminger) Birkhauser Verlag, Basel, 1980 vol. 2, pp. 365-370.

[2] G. Várhegyi, M. J. Antal, Jr., T. Székely, F. Till, E. Jakab and P. Szabó: Simultaneous thermogravimetric mass spectrometric studies on the thermal decomposition of biopolymers. Part 1: Avicel cellulose in the presence and absence of catalysts. Part 2: Sugar cane bagasse in the presence and absence of catalysts. Energy Fuels, 2 (1988) 273-277 and 267-272.

[3] I. Simkovic, G. Várhegyi, M. J. Antal, Jr., A. Ebringerova, T. Székely, P. Szabó: TG/MS characterization of the thermal decomposition of (4-O-methyl-D-glucurono)-D-xylan. J. Appl. Polym. Sci., 36 (1988) 721-728.

[4] G. Várhegyi, E. Jakab, F. Till and T. Székely: Thermogravimetric - mass spectrometric characterization of the thermal decomposition of sunflower stem. Energy Fuels, 3 (1989) 755-760.

[5] E. Jakab, O. Faix and F. Till: Thermal decomposition of milled wood lignins studied by thermogravimetry/mass spectrometry. J. Anal. Appl. Pyrolysis, 40-41 (1997) 171-186.

[6] M. Blazsó, T. Székely, F. Till, G. Várhegyi, E. Jakab and P. Szabó: Pyrolysis GC-MS and TG-MS investigation of brown coals. J. Anal. Appl. Pyrolysis, 8 (1985) 255-269.

[7] E.Jakab, F.Till and G. Várhegyi: Thermogravimetric-mass spectrometric study on the low temperature oxidation of coals Fuel Proces. Technol., 28 (1991) 221-238

[8] E. Jakab, F. Till, T. Székely, S. S. Kozhabekov and B. A. Zhubanov: Thermal Decomposition of ArylAlicyclic Polyimides Studied by Thermogravimetry/Mass Spectrometry and Pyrolysis-Gas Chromatography/Mass Spectrometry. J. Anal. Appl. Pyrolysis, 23 (1992) 229-243

[9] S. Pekker, G. Faigel, K. Fodor-Csorba, L. Gránásy, E. Jakab and M. Tegze: Structure and Stability of Crystalline $\mathrm{C}_{60} . \mathrm{n}$-pentane Clathrate. Solid State Commun., 83 (1992) 423-426.

[10] G. Várhegyi, P. Szabó, E. Jakab, F. Till, J-R. Richard: Mathematical modeling of char reactivity in Ar- $\mathrm{O}_{2}$ and $\mathrm{CO}_{2}-\mathrm{O}_{2}$ mixtures. Energy Fuels, 10 (1996) 1208-1214.

[11] M. J. Antal, Jr., G. Várhegyi, E. Jakab: Cellulose Pyrolysis Kinetics: Revisited. Ind. Eng. Chem. Res., 37 (1998) 1267-1275.

[12] G. Várhegyi, M. J. Antal, Jr., E. Jakab and P. Szabó: Kinetic modeling of biomass pyrolysis. J. Anal. Appl. Pyrolysis, 42 (1997) 73-87.

[13] E. T. Whittaker and G. Robinson: The calculus of observations. Blackie \& Son, London, 1926.

[14] C. H. Reinsch: Smoothing by spline functions, Numerische Mathematik, 10 (1967) 177-183.

[15] A. Savitzky and M. Golay: Smoothing + differentiation of data by simplified least squares processes. Anal. Chem. 36 (1964) 1627.

[16] K. Y. Hui and M. Gratzl: Anomalies of convolutional smoothing and differentiation. Anal. Chem. 68 (1995) 1054-1057. 